\title{
ANALISIS MATEMATIS PENGURANGAN PADA BILANGAN BULAT DENGAN PENGGUNAAN DEKAK-DEKAK DI MI NURUL HUDA
}

\author{
Nurdyansyah \\ Universitas Muhammadyah Sidoarjo, Sidoarjo, Indonesia \\ nurdyansyah@umsida.ac.id
}

\begin{abstract}
Abstrack
This study aims to describe (1) how to improve the understanding of the concept of integer reduction through the use of class V MI MI Nurul Huda learners, (2) the use of decks can help improve understanding of the concept of reducing numbers. This study uses a PTK design. The subjects of this study were 23 grade $V$ students. The instruments used to collect data are observation sheets, tests, and interviews. The data analysis technique used is the t-test. The results of this study indicate that the reduction in integers with the use of decks is done in stages (1) understanding the concept, (2) determining the concept, and (3) stabilizing the material. At the stage of understanding the concept of students as a group guided by educators using media click, (a) students divide red and black beads, (b) do the work of reducing the integers by moving red or black beads in place to looking for the results of subtracting integers. The use of approach can help improve the understanding of integer concepts in class V MI Nurul Huda students can be seen from the t-test value which states there is an increase in understanding by 32\% from before. The average test scores of students in the first cycle (65.9) and have increased in the second cycle (83.3). Based on the results of the study, it is suggested: (1) educators in mathematics learning activities should be able to use the media approach to the concept of integers, (2) to mathematics educators in order to conduct the same
\end{abstract}


action research or develop this research in other classes at MI Nurul Huda on an ongoing basis.

Keyword: understanding of the concept, reducing numbers.

\begin{abstract}
Abstrak
Penelitian ini bertujuan untuk mendiskripsikan (1) cara meningkatkan pemahaman konsep pengurangan bilangan bulat melalui penggunaan dekak-dekak peserta didik kelas V MI Nurul Huda, (2) penggunaan dekak-dekak dapat membantu meningkatkan pemahaman konsep pengurangan bilangan. Penelitian ini menggunakan rancangan PTK. Subyek penelitian ini adalah peserta didik kelas $\mathrm{V}$ sebanyak 23 peserta didik. Instrumen yang digunakan untuk mengumpulkan data adalah lembar observasi, tes, dan wawancara. Teknik analisis data yang dipakai adalah t-tes. Hasil penelitian ini menunjukkan bahwa pengurangan pada bilangan bulat dengan penggunaan dekak-dekak dilakukan dengan tahap (1) pemahaman konsep, (2) penentuan konsep, dan (3) pemantapan materi. Pada tahap pemahaman konsep peserta didik secara kelompok dibimbing oleh pendidik menggunakan media dekak-dekak, (a) peserta didik membagi manik-manik berwarna merah dan hitam, (b) melakukan pengerjaan pengurangan bilangan bulat dengan memindaahkan manikmanik merah atau hitam pada tempatnya untuk mencari hasil pengurangan bilangan bulat. Penggunaan dekak-dekak dapat membantu meningkatkan pemahaman konsep bilangan bulat peserta didik kelas V MI Nurul Huda dapat dilihat dari nilai t-tes yang menyatakan ada peningkatan pemahaman sebesar $32 \%$ dari sebelumnya. Adapun rata-rata nilai tes peserta didik pada siklus I $(65,9)$ dan mengalami peningkatan pada siklus II $(83,3)$. Berdasarkan hasil penelitian, disarankan: (1) kepada pendidik dalam kegiatan pembelajaran matematika hendaknya dapat menggunakan media dekak-dekak pada konsep bilangan bulat, (2) kepada pendidik matematika agar dapat melakukan penelitian tindakan yang sama atau mengembangkan penelitian ini pada kelas-kelas yang lain di MI Nurul Huda secara berkesinambungan.
\end{abstract}

Kata Kunci: Analisis Matematis, Pengurangan bilangan bulat, penggunaan dekak-dekak. 


\section{A. Pendahuluan}

\section{Latar Belakang}

Matematika merupakan ilmu dasar yang menjadi alat untuk mempelajari ilmu-ilmu lain (Antonius, 2006: 1). Oleh karena itu penguasaan matematika mutlak diperlukan. Salah satu tujuan pembelajaran matematika dalam Kurikulum 2013 adalah agar peserta didik memiliki kamampuan memahami konsep matematika dan diintegrasikan kepada lingkungan sekitar.

Berdasarkan hasil pengamatan dan wawancara dengan wali kelas V dapat dilihat bahwa pada semester II tahun pelajaran 20172018 hasil belajar peserta didik pada pelajaran matematika hanya mencapai rata-rata 52,4 apabila dibandingkan dengan nilai ratarata mata pelajaran lain matematika menduduki peringkat teredah padahal menurut KKM nilai minimal adalah $70 \%$ dengan nilai yang dicapai adalah 70 .

Melihat fakta yang terjadi pada peserta didik tersebut, perlu dilakukan tindakan agar peserta didik memahami konsep bilangan bulat serta mampu menerapkan dalam kehidupan sehari-hari. Tindakan dilakukan dengan menggunakan dekak-dekak dalam menyelesaikan operasi hitung pengurangan bilangan bulat. Dengan dasar penilaian di atas tersebut MI Nurul Huda belum pernah menggunakan media dekak-dekak dalam pembelajaran matematika pada tema bilangan bulat.

\section{Hipotesis}

Berdasarkan rumusan masalah di atas, dapat dikemukan jawaban sementara bahwa dengan menggunakan dekak-dekak, dapat meningkatkan pemahaman konsep bilangan bulat peserta didik kelas V MI Nurul Huda.

\section{Metode Penelitian}

\section{a. Rancangan Penelitian}

Penelitian ini menggunakan rancangan Penelitian Tindakan Kelas (PTK) yang berusaha mengkaji dan merefleksi secara mendalam tentang cara mengatasi kesulitan peserta didik, dalam 
pembelajaran matematika operasi hitung bilangan bulat dengan menggunakan dekak-dekak untuk menyelesaikan soal penjumlahan dan pengurangan. Menurut (Dasna, 2007) menyatakan Pengertian PTK merupakan studi sistematis yang dilakukan oleh pendidik dalam upaya memperbaiki praktik-praktik dalam Pendidikan dengan melakukan tindakan praktis-praktis dalam pendidikan dengan melakukan tindakan praktis serta refleksi dari tindakan tersebut. Bila pendidik menemukan keadaan kelas yang kurang memuaskan atau kurang mendukung kondisi belajar maka pendidik harus "Melakukan sesuatu" atau "Melakukan Tindakan" agar kondisi tersebut tidak menjadi Inhibator (penghambat) Proses Pembelajaran. (Arikunto, S. 2002)

Penelitian tindakan kelas ini menggunakan model kolaborasi yang mengutamakan kerjasama antar Kepala sekolah, pendidik, dan peneliti. Penelitian ini dibagi dalam 2 siklus yang disesuaikan dengan alokasi waktu atau materi yang dipilih, masing-masing siklus terdiri dari 4 langkah. Menurut Dasna (2007) menyampikan bahwa langkah PTK terdiri dari (1) Perencanaan, (2) Tindakan, (3) Pengamatan, dan (4) Refleksi.

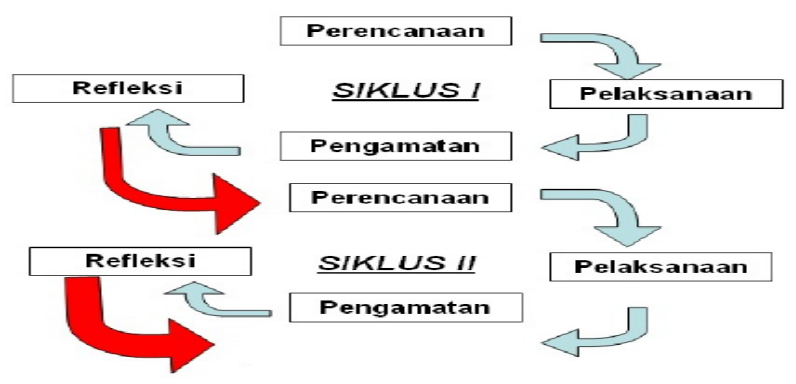

Gambar 1.1 Model Kemmis dan Taggarat

\section{b. Lokasi dan Subyek Penelitian}

Penelitian tindakan kelas ini dilaksanakan di MI Nurul Huda untuk mata pelajaran matematika kelas V. Alasan peneliti mengambil lokasi ini karena ditemukan masalah bahwa mulai kelas IV sampai kelas $\mathrm{V}$ mayoritas peserta didik kesulitan dalam memahami fakta dasar pengurangan bilangan bulat. 
Dalam Penelitian Tindakan Kelas (PTK) ini, yang menjadi subyek penelitian adalah peserta didik kelas V MI Nurul Huda yang terdiri dari 23 peserta didik dengan komposisi 9 laki-laki dan 14 perempuan.

\section{c. Teknik Pengumpulan data dan analisis data}

Sugiono (2015) dan Arikunto (2001) menjelaskan bahwa teknik pengumpulan data dibagi menjadi 4 yaitu angket, observasi, wawancara dan dokumentasi. dalam penelitian ini teknik pengumpulan data menggunakan observasi, wawancara dan dokumentasi. Adapun teknik analisis data menggunakan T-Tes.

\section{B. Pembahasan}

\section{Pembelajaran Matematika}

Menurut Asyari (1998) dalam matematika ada 2 pengetahuan yang dapat di pelajari, yaitu pengetahuan konseptual dan pengetahuan prosedural. Kedua pengetahuan itu mempunyai peran yang sama pentingnya dan keduanya perlu diajarkan di sekolah.

Pengetahuan konseptual mengacu pada ketrampilan melakukan sesuatu prosedur pengajaran menurut Karso (2004), kegiatan pembelajaran dikelompokkan menjadi 3 tahap yaitu kegiatan pembelajaran untuk penanaman konsep, pemahaman konsep, dan pembinaan ketrampilan. Berikut ini adalah pemaparan dari ketiga kegiatan pembelajaran di atas.

\section{a. Kegiatan Pembelajaran dengan Penanaman Konsep}

Yaitu untuk menyampaikan konsep-konsep baru yang umumnya merupakan jenis konsep dasar. Pembelajaran penanaman konsep dasar merupakan jembatan yang harus dapat menghubungkan kemampuan pengetahuan peserta didik yang konkret dengan konsep matematika yang abstrak. (Dimyati, 2006)

Dalam penanaman konsep bilangan bulat kita bisa menggunakan contoh dalam kehidupan sehari-hari, misalnya untuk menjelaskan bilangan bulat positif Ani maju tiga langkah sedangkan Adi mundur dua langkah adalah bilangan bulat negatif kalimat "Ani maju sebanyak 3 langkah" diganti dengan "Ani maju sebanyak 
positif tiga (+3) langkah". Kalimat "Adi mundur dua langkah" diganti dengan "Adi mundur sebanyak negatif dua (-2)" lambang + untuk bilangan positif tidak perlu ditulis, jadi untuk +3 cukup ditulis 3 saja.

\section{b. Kegiatan Pembelajaran dengan Pemahaman Konsep}

Joyce (1992) dan Edgar (1998) Model pembelajaran dengan pendekatan pemahaman konsep adalah proses kegiatan belajar mengajar yang merupakan kelanjutan dari model pendekatan penanaman konsep. Dalam pemahaman konsep proses pembelajarannya memberi penekanan agar peserta didik menguasai ciri-ciri, sifat-sifat dan penerapan dari konsep yang telah dipelajarinya pada tahap penanaman konsep misalnya untuk mengenalkan penjumlahan bilangan bulat menggunakan potongan-potongan manila berukuran $2 \times 2 \mathrm{~cm}$ dengan 2 warna. Warna merah untuk bilangan bulat positif dan warna hitam untuk bilangan bulat negatif. (Hudaya, 1990) \& (Murni, 2005)

\section{Contoh :}

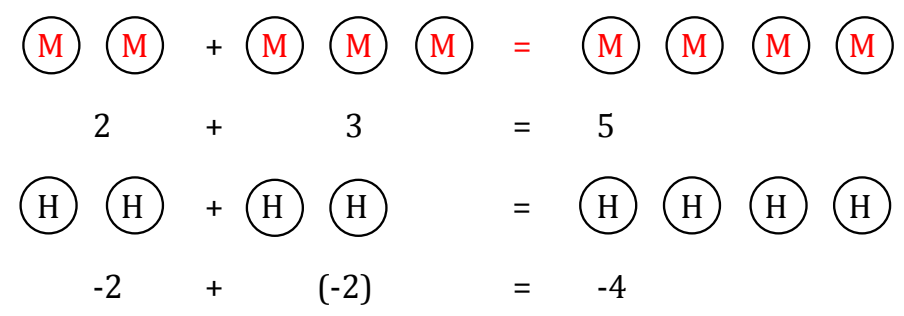

\section{c. Kegiatan Pembelajaran dengan Pembinaan Ketrampilan}

Proses pembelajaran pada tahap pembinaan ketrampilan ini bertujuan untuk melatih peserta didik mengingat dan menerapkan konsep yang sudah dipelajarinya pada kedua tahapan pembelajaran di atas tadi. (Pitajeng, 2006) Setelah peserta didik memahami penjumlahan dan pengurangan bilangan bulat barulah peserta didik diberikan soal-soal latihan untuk lebih memantapkan pemahaman. Seperti pada contoh soal berikut:
$1.4-6=\ldots$.
2. $4-(-6)=\ldots$.
3. $-7-(-3)=\ldots$
4. $-8-8=\ldots$.
5. $-18-12=\ldots$.
6. $-25-(-16)=\ldots$ 


\section{d. Bilangan Bulat}

Yang dimaksud dengan bilangan bulat adalah gabungan dari bilangan cacah dan bilangan negatif. Bilangan negatif adalah pasangan bilangan asli yang jika di jumlahkan hasilnya sama dengan nol.

Kegiatan untuk membantu peserta didik mengenal konsep bilangan bulat dapat menggunakan contoh dalam kehidupan seharihari. Contoh pernyataan dalam keseharian misalnya Doni maju sebanyak 3 langkah dan Mardi mundur 3 langkah. Penggunaan contoh di atas digunakan untuk mengenal bilangan bulat positif dan bilangan bulat negatif. Sedangkan kegiatan untuk membantu peserta didik memahami konsep pengurangan bilangan bulat dengan menggunakan dekak-dekak (benda konkret) contoh: $3-(-2)=\ldots$.

Peserta didik mengambil 3 biji dekak-dekak merah dan 2 biji dekak-dekak hitam kemudian memasangkan pada dekak-dekak sehingga seperti ini gambarnya:

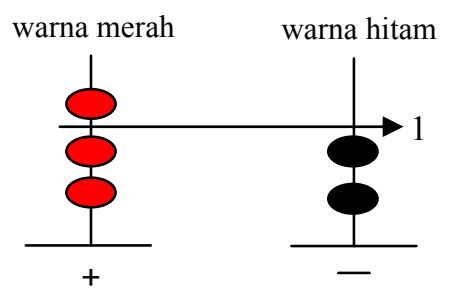

Ada 1 biji dekak-dekak yang tidak mempunyai pasangan hal ini dapat disimpulkan bahwa $3+(-2)=1$

\section{Operasi Bilangan Bulat}

Prihandoko (2006) menjelaskan bahwa ada empat operasi bilangan bulat yang dikenalkan untuk bilangan bulat, yaitu operasi penjumlahan, pengurangan, pembagian dan perkalian. Keempat operasi ini saling berkaitan sehingga penguasaan ini meliputi pemahaman konsep dan ketrampilan melakukan operasi. (Ruseffendi, 1992). Namun pada penelitian ini hanya terbatas pada operasi hitung penjumlahan dan pengurangan bilangan bulat yaitu untuk bilangan bulat positif-positif, positif-negatif, negatif-negatif dan negatif-positif. Tahapan pada pembelajaran operasi hitung 
bilangan bulat dengan menggunakan dekak-dekak dibagi menjadi 3 tahap.

Tahap pertama mengenalkan nilai tempat.

Contoh :
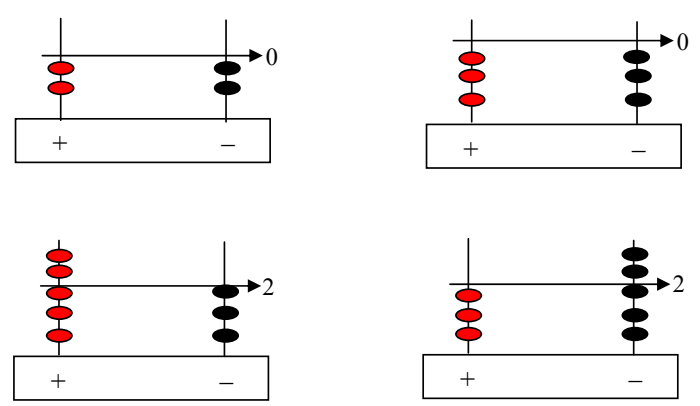

Tahap Kedua Penjumlahan Bilangan Bulat

1) Positif dengan Positif

Contoh :
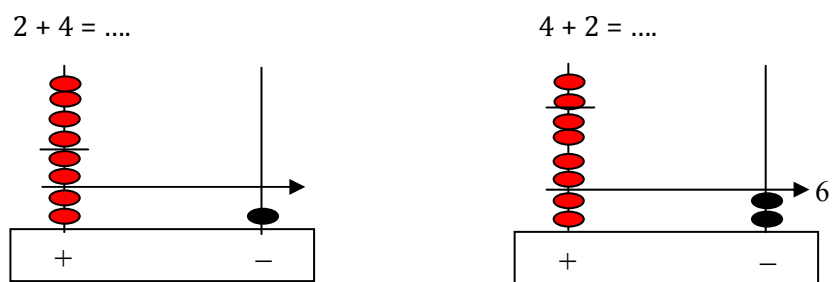

2) Positif dengan Negatif

Contoh :

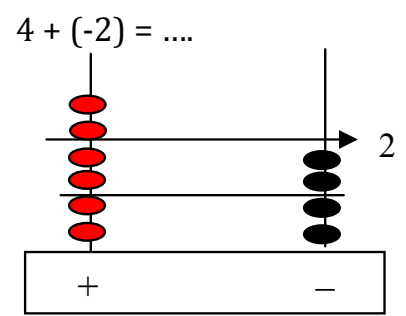


3) Negatif dengan Positif

Contoh :
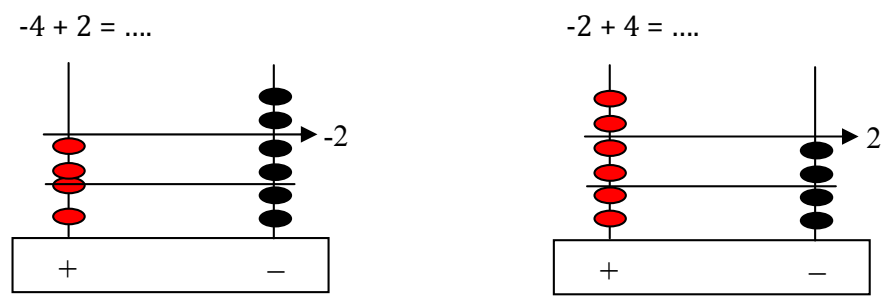

4) Negatif dengan Negatif

Contoh :
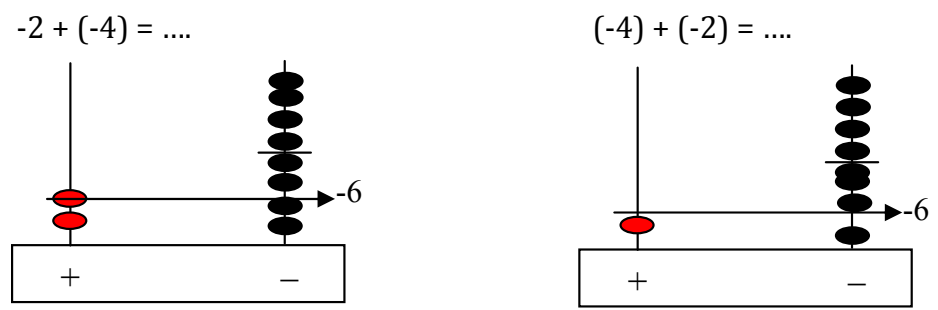

Tahap ke tiga Pengurangan Bilangan Bulat

5) Positif dengan Positif

Contoh :
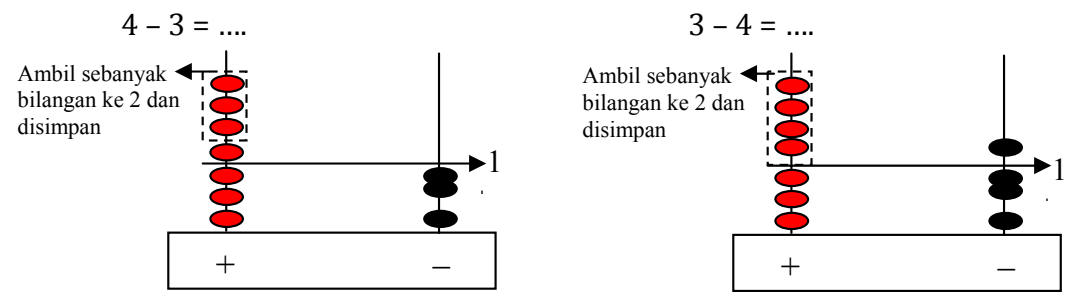

6) Positif dengan Negatif

Contoh :
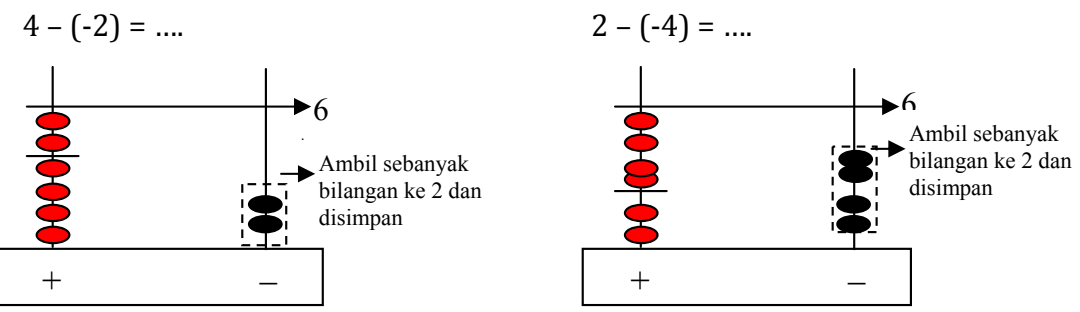

Elementary Vol. 7 No. 2 Juli-Desember 2019 
7) Negatif dengan Positif

Contoh :

$-2-4=\ldots$

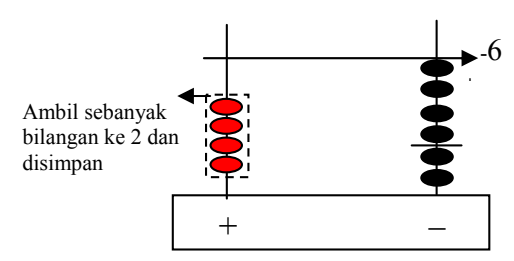

$-4-2=\ldots$

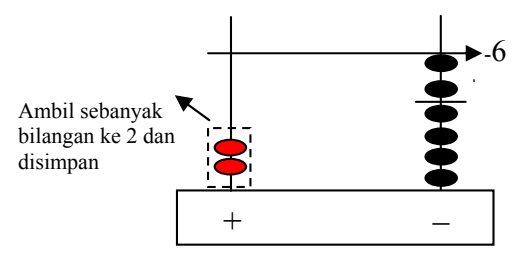

8) Negatif dengan Negatif Contoh :

$-2-(-4)=\ldots$.

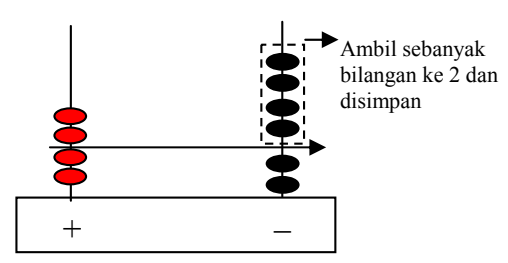

$-4-(-2)=\ldots$

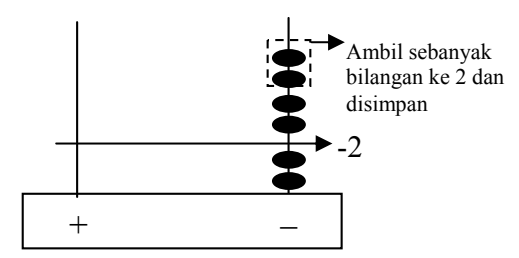

\section{Hasil Penelitian}

Berdasarkan hasil tes dan hasil belajar peserta didik pada pelaksanaan siklus I sebagai berikut :

Tabel 4.1 Distribusi Skor pada Tes Siklus I

\begin{tabular}{|l|l|l|l|}
\hline \multicolumn{1}{|c|}{ Skor } & \multicolumn{1}{c|}{ Kategori } & \multicolumn{1}{c|}{ Frekuensi } & \multicolumn{1}{c|}{ Persentase } \\
\hline $0-39$ & Sangat rendah & - & - \\
$40-54$ & Rendah & 15 & $65 \%$ \\
$55-74$ & Sedang & 3 & $13 \%$ \\
$75-89$ & Tinggi & 3 & $13 \%$ \\
$90-100$ & Sangat Tinggi & 2 & $9 \%$ \\
\hline Jumlah & & 23 & 100 \\
\hline
\end{tabular}

Dari hasil ini diperoleh informasi bahwa peserta didik yang belum tuntas belajar sebanyak 15 peserta didik (65\%) dengan kategori rendah, 3 peserta didik (13\%) dengan kategori sedang, dan yang mencapai ketuntasan sebanyak 5 peserta didik (22\%). Dari hasil ini diperoleh keterangan bahwa ketuntasan belum mencapai KKM secara klasikal yaitu $70 \%$. 
Hasil pengamatan yang dilakukan pada siklus I, diperoleh darai pengamatan yang mencakup (1) kerjasama, (2) keberanian, (3) aktivitas, dan (4) ketepatan.

Tabel 4.2 Perolehan Skor Efektifitas Peserta didik dalam PBM Siklus I dan II

Persentasi Peningkatan Hasil Nilai Tes Peserta didik Pada Siklus I dan Siklus II

\begin{tabular}{|c|c|c|c|c|c|}
\hline \multirow[b]{2}{*}{ No } & \multirow[b]{2}{*}{$\begin{array}{c}\text { Nama Peserta } \\
\text { didik }\end{array}$} & \multirow[b]{2}{*}{$\begin{array}{c}\text { Nilai Siklus } \\
\text { I }\end{array}$} & \multirow[b]{2}{*}{$\begin{array}{c}\text { Nilai Siklus } \\
\text { II }\end{array}$} & \multicolumn{2}{|c|}{ Ktuntasan } \\
\hline & & & & $\begin{array}{l}\text { Siklus I } \\
\text { Tuntas }\end{array}$ & $\begin{array}{c}\text { Siklus II } \\
\text { Tuntas }\end{array}$ \\
\hline 1 & TKN & 50 & 70 & - & \\
\hline 2 & SD & 100 & 100 & & \\
\hline 3 & BW & 70 & 80 & & \\
\hline 4 & IR & 70 & 80 & & \\
\hline 5 & RF & 60 & 80 & - & \\
\hline 6 & FY & 50 & 70 & - & \\
\hline 7 & SR & 40 & 70 & - & \\
\hline 8 & FZ & 80 & 90 & & \\
\hline 9 & RI & 30 & 70 & - & \\
\hline 10 & LF & 40 & 75 & - & \\
\hline 11 & LM & 50 & 75 & - & \\
\hline 12 & MA & 40 & 70 & - & \\
\hline 13 & MM & 50 & 70 & - & \\
\hline 14 & $\mathrm{MH}$ & 100 & 100 & 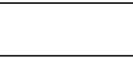 & \\
\hline 15 & MAA & 60 & 80 & - & \\
\hline 16 & MHK & 40 & 75 & - & \\
\hline 17 & DF & 50 & 80 & - & \\
\hline 18 & MRT & 50 & 80 & - & \\
\hline 19 & BA & 40 & 75 & - & \\
\hline 20 & ST & 70 & 90 & & \\
\hline 21 & NS & 100 & 100 & & \\
\hline 22 & NM & 70 & 90 & & \\
\hline 23 & PA & 90 & 100 & & \\
\hline & Persentase tuntas & $23 \%$ & $100 \%$ & & \\
\hline & $\begin{array}{l}\text { Persentase belum } \\
\text { tuntas }\end{array}$ & $77 \%$ & $0 \%$ & & \\
\hline
\end{tabular}


Dari data hasil aktifitas peserta didik kelas V MI Nurul Huda yang berjumlah 23 peserta didik yang mengikuti siklus I adalah 23 peserta didik, sedangkan hasil yang dijaring melalui lembar pengamatan pada tabel 4.2 diketahui bahwa perolehan skot tetinggi pada siklus 1 adalah 100 dan terendah adalah 30 sedangkan pada siklus II nilai tertinggi adalah 100 dan skor terendah 70. Prosentasi siklus 1 yang belum tuntas mencapai $77 \%$ sedangkan pada siklus II sebesar) \%

Dengan demikian, dapat dikatakan bahwa proses belajar mengajar matematika pengurangan bilangan bulat sudah mencapai hasil yang maksimal (tuntas) sesuai dengan KKM yang ditargetkan.

\section{Observasi}

\section{a. Hasil observasi aktivitas pendidik dalam PBM.}

Berdasarkan hasil observasi aktivitas pendidik dalam kegiatan belajar mengajar pada siklus II dikelas V MI Nurul Huda secara konvensional adalah sebagai berikut:

Tabel 4.3 Perolehan Skor Aktifitas Pendidik dalam PBM siklus II

\begin{tabular}{|c|l|c|c|c|}
\hline NO & \multicolumn{1}{|c|}{ KEGIATAN } & A & B & C \\
\hline 1. & Apersepsi & V & & \\
\hline 2. & Penjelasan materi pengurangan bilangan bulat & & $\sqrt{ }$ & \\
\hline 3. & Teknik pembagian kelompok & & $\sqrt{ }$ & \\
\hline 4. & Pengelolaan kegiatan diskusi kelompok & & $\sqrt{ }$ & \\
\hline 5. & Kemampuan menyimpulkan hasil diskusi & & & $\sqrt{ }$ \\
\hline 6. & Kemampuan melakukan evaluasi & & & $\sqrt{ }$ \\
\hline 7. & Memberikan penghargaan individu dan kelompok & & $\sqrt{ }$ & \\
\hline 8. & Menentukan nilai individu dan kelompok & & $\sqrt{ }$ & \\
\hline 9. & Menyimpulkan materi pembelajaran & & $\sqrt{ }$ & \\
\hline 10. & Menutup pelajaran & & $\sqrt{ }$ & \\
\hline
\end{tabular}

Keterangan :

A dengan nilai skor 4

B dengan nilai skor 3

C dengan nilai skor 2

$\mathrm{D}$ dengan nilai skor 1 
Pada tabel 4.3 tergambar bahwa aktifitas pendidik dalam PBM pada siklus satu masih rendah dengan perolehan skor 29 (53\%) dari skor idealnya adalah 40, dengan demikian dapat dikatakan bahwa aktifitas pendidik dalam mengajar pengurangan bilangan bulat belum maksimal.

\section{b. Wawancara Peserta didik}

Wawancara terhadap peserta didik bertujuan untuk mengetahui hambatan yang dialami peserta didik dalam mengikuti pembelajarn matematika pengurangan bilangan bulat. Berikut ini hasil wawancara antara peneliti dengan salah satu peserta didik:

\begin{tabular}{|l|l|l|}
\hline Peneliti & $:$ & $\begin{array}{l}\text { Apakahkalian senang dengan pembelajaran matematika } \\
\text { pengurangan bilangan bulat yang baru kalian ikuti? } \\
\text { Mengapa? }\end{array}$ \\
\hline Peserta Didik & $: \begin{array}{l}\text { Kurang menyenangkan karena menjelaskan saja } \\
\text { (ceramah) }\end{array}$ \\
\hline Peneliti & $: \begin{array}{l}\text { Dalam memahami konsep operasi hitung penjumlahan } \\
\text { dan pengurangan bilangan bulat, cara manakah yang } \\
\text { paling kalian sukai? Mengapa? }\end{array}$ \\
\hline Peserta Didik & $:$ & $\begin{array}{l}\text { Cara yang saya sukai jika guu mengguankan media/ } \\
\text { alat peraga }\end{array}$ \\
\hline Peneliti & $: \begin{array}{l}\text { Menurut pendapat kalian dalam menyelesaikan operasi } \\
\text { hitung penjumlahan dan pengurangan bilangan bulat, } \\
\text { perlukah bimbingan pendidik? }\end{array}$ \\
\hline Peserta Didik & $:$ Sangat perlu \\
\hline Peneliti & $: \begin{array}{l}\text { Apakah kalian dapat memahami materi pelajaran yang } \\
\text { baru kalian ikuti? }\end{array}$ \\
\hline Peserta Didik & $: \begin{array}{l}\text { Saya kurang dapat memahami materi yang baru } \\
\text { diajarkan pendidik. }\end{array}$ \\
\hline
\end{tabular}

Berdasarkan hasil wawancara diatas dapat disimpukan bahwa pembelajaran matematika pengurangan bilangan bulat yang dilakukan secara konvensional tidak menunjukkan pembelajaran yang dapat merangsang peserta didik untuk belajar aktif, kreatif dan menyenangkan sehingga berakibat pada hasil belajar peserta didik yang kurang maksimal (tidak tuntas). 


\section{c. Hasil Wawancara Pendidik}

\begin{tabular}{|l|l|l|}
\hline Peneliti & $: \begin{array}{l}\text { Bagaimana pendapat anda tentang PBM yang dilakukan } \\
\text { oleh pendidik? }\end{array}$ \\
\hline Guru Kelas & $: \begin{array}{l}\text { Cukup, perlu ditingkatkan lagi supaya kegiatan belajar } \\
\text { mengajar berjalan lebih baik lagi }\end{array}$ \\
\hline Peneliti & $:$ & Pada bagian mana yang sudah baik? \\
\hline Guru Kelas & $:$ & Pada proses pembelajaran \\
\hline Peneliti & $:$ & Pada bagian mana yang masih perlu diperbaiki? \\
\hline Guru Kelas & $: \begin{array}{l}\text { Yang perlu diperbaiki pemanfaatan media pelajaran dan } \\
\text { keaktifan peserta didik }\end{array}$ \\
\hline Peneliti & $: \begin{array}{l}\text { Apakah Anda yakin bahwa pembelajaran matematika } \\
\text { operasi hitung bilangan bulat dapat meningkatkan } \\
\text { partisipasi dan hasil belajar? Berikan alasannya! }\end{array}$ \\
\hline Guru Kelas & $: \begin{array}{l}\text { Kurang yakin karena dalam menerangkan tentang } \\
\text { pemahaman konsep, bilangan bulat hanya ceramah dan } \\
\text { tanya jawab saja, tidak didukung dengan penggunaan } \\
\text { media. }\end{array}$ \\
\hline Peneliti & $:$ & Apakah saran Anda untuk perbaikan PBM selanjutnya? \\
\hline Guru Kelas & $: \begin{array}{l}\text { Agar dapat memanfaatkan media yang sesuai dengan } \\
\text { tujuan pembelajaran }\end{array}$ \\
\hline
\end{tabular}

\section{Refleksi}

\section{a. Pemanfaatan media tidak ada}

Berdasarkan cuplikan hasil wawancara di atas dapat disimpulkan bahwa pembelajaran matematika pengurangan bilangan bulat yang dilakukan secara konvensional yang tidak menggunakan media pembelajaran dan hanya mengandalkan dengan ceramah dan tanya jawab saja dapat mengakibatkan hasil belajar peserta didik kurang maksimal. Untuk itu perlu adanya siklus berikutnya, guna memperbaiki kekurangan pada PBM siklus I.

Berdasarkan hasil siklus II terlihat bahwa KKM yang dicanangkan sudah sesuai target karena pendidik telah melakukan perbaikan pembelajaran dengan menggunakan dekakdekak. Sehingga dekak-dekak dapat direkomendasikan untuk dipergurnakan guru dalam peningkatan perhitungan pada mata pelajaran matematika kelas V. 


\section{Simpulan}

Penggunaan dekak-dekak dapat membantu meningkatkan pemahaman konsep bilangan bulat peserta didik kelas V di MI Nurul Huda dapat dilihat dari hasil nilai tes peserta didik pada siklus I dan mengalami peningkatan pada siklus II. Pada siklus I peserta didik yang belum tuntas belajar sebanyak $77 \%$ Sedangkan pada siklus II seluruh peserta didik sudah tuntas belajar 100\%. Dari hasil ini diperoleh keterangan bahwa seluruh peserta didik mencapai standar KKM secara klasikal yaitu 100\%, sehingga penggunaan alat peraga dekak-dekak dapat dipergunakan dalam peningkatan perhitungan matematika di MI kelas V. 


\section{DAFTAR PUSTAKA}

Arikunto, S. Prosedur Penelitian Satuan Suatu Pendekatan Praktek. Yogyakarta : Bumi Akasara, 2001.

Arikunto, S. Dasar-dasar Evaluasi Pendidikan..Yogyakarta : Rineka Cipta, 2002.

Asyari, A.R, dkk. Pendidikan Matematika I.Jakarta : Proyek PGSD Dirjen Dikti Depdikbud, 1998.

Dasna, W. I, Fatchan, A. Penelitian Tindakan Kelas dan Karya Ilmiah. Malang : BSPG Rayon 15 Universitas Negeri Malang. 2007.

Depdiknas.. Standar Kompetensi Dan Kompetensi Dasar Kurikulum 2006. Jakarta: Depdiknas, 2007

Depdiknas.. Pedoman Penilaian Hasil Belajar SD.Jakarta : Depdiknas, 2007

Dimyati. Belajar dan Pembelajaran.Jakarta : Rineka Cipta2006.

Edgar dan kavohak.. Strategies for Teachers:Second Edition.New Yersey : Pentice Hall, 1998

Hudaya, H.. Strategi Mengajar Belajar Matematika. Malang : IKIP Malang, 1990

Joyce and Will, M.. Models of Teaching.Massachussetts : Allyn and Bacon, 1992.

Karso, dkk.. Pendidikan Matematika I. Jakarta : Universitas Terbuka, 2004

Mariana, M.A. Pembelajaran Remedial. Jakarta : Depdiknas, 2003.

Murni, S..Analisis Kendala Peserta didik Kelas II SD dan Penerapan Pengoprasian Hitung Dasar Bilangan Cacah. Studi Kasusu. Malang : FKIP.UT, 2005

Pitajeng. Pembelajan Matematika yang Menyenangkan. Jakarta: Depdiknas, 2006.

Prihandoko, C.A. Pemahaman dan Penyajian Konsep Matematika secara Benar dan Menarik.Jakarta : depdiknas, 2006

Ruseffendi, E.T..Materi Pokok Pendidikan Matematika 3. Jakarta : Depdikbud. 1992 
Analisis Matematis Pengurangan pada Bilangan Bulat... |383

Sugiono. Metode Penelitian dan pengembangan. Cetakan ke-1. Bandung: PT Alfabeta, 2015

Wardhani, dkk.. Strategi Mengoptimalkan Hasil Belajar Calistung di Sekolah Dasar.Yogyakarta: depdiknas, 2006

Elementary Vol. 7 No. 2 Juli-Desember 2019 
384| Nurdyansyah

Elementary Vol. 7 No. 2 Juli-Desember 2019 